\title{
Treatment of Gram-Negative Septic Shock with Human IgG Antibody to Escherichia coli J5: A Prospective, Double-Blind, Randomized Trial
}

\author{
Thierry Calandra, Michel P. Glauser, Joop \\ Schellekens, Jan Verhoef, and the Swiss-Dutch J5 \\ Immunoglobulin Study Group
}

\author{
From the Division of Infectious Diseases, Department of \\ Internal Medicine, Centre Hospitalier Universitaire Vaudois, \\ Lausanne, Switzerland; and the Department of Clinical \\ Bacteriology, University Hospital, Utrecht, the Netherlands
}

In a randomized, double-blind, multicenter trial we compared the efficacy of a preparation of human IgG antibody to Escherichia coli J5 (J5-IVIG) with that of a standard IgG preparation (IVIG) for the treatment of gram-negative septic shock. At study entry, patients received a single intravenous dose of $200 \mathrm{mg} / \mathrm{kg}$ of body weight (maximal dose, $12 \mathrm{~g}$ ) of either J5-IVIG or IVIG. Of the 100 patients randomized, 71 (30 receiving J5IVIG and 41 receiving IVIG) had a documented gram-negative infection. Mortality from gram-negative septic shock was 50\% (15 of 30) in J5-IVIG recipients and 49\% (20 of 41) in IVIG recipients. In addition, treatment with J5-IVIG did not reduce the number of systemic complications of shock and did not delay the occurrence of death due to septic shock. Thus we conclude that J5-IVIG was not superior to IVIG in reducing mortality or in reversing gram-negative septic shock.

Episodes of gram-negative bacteremia are associated with a death rate of $20 \%-30 \%$ [1-3], but in patients developing septic shock, fatality ratios are in the range of $50 \%-80 \%$ [4]. Because advances in an-

Received for publication 19 November 1987 and in revised form 7 March 1988.

This trial was conducted in accordance with the guidelines laid down in the Declaration of Helsinki and was approved by the Human Subjects and Ethics Committees of the participating centers. Depending on the patient's clinical condition, the informed consent was given either by the patient or by the physician in charge of the patient.

This work was presented in part (abstract no. 736) at the 26th Interscience Conference on Antimicrobial Agents and Chemotherapy, held on 28 September-1 October 1986, in New Orleans, Louisiana.

The principal investigators and the participating centers in the Swiss-Dutch J5 Immunoglobulin Study Group were as follows: J. Schellekens and J. Verhoef, University Hospital, Utrecht, the Netherlands (28 patients); E. Kalter, Sint Radboudziekenhuis, Nijmegen, the Netherlands (17 patients); W. Zimmerli, Kantonsspital, Basel, Switzerland (16 patients); T. Calandra and M. P. Glauser, Centre Hospitalier Universitaire Vaudois, Lausanne, Switzerland (12 patients); A. Nicole and C. Regamey, Hôpital Cantonal, Fribourg, Switzerland (8 patients); P. Suter and B. Hirschel, Hôpital Cantonal Universitaire, Geneva, Switzerland (7 patients); A. Schaffner, Universitätsspital, Zurich, Switzerland (6 patients); P. Erard, Hôpital des Cadolles, Neuchâtel, Switzerland (4 patients); L. Mater and C. P. Naumann, Institut für Klinische Mikrobiologie und Immunologie and Kantonsspital, St. Gallen, Switzerland (2 patients); and G. Dupuis, Hôpital Regional, Sion, Switzerland (1 patient).

This work was supported by Sandoz AG (Basel), Sandoz Forschungsinstitut (Vienna, Austria), and the Central Laboratory of the Swiss Red Cross (Bern, Switzerland). timicrobial therapy have not had a major impact on lowering the lethality of septic shock, other therapeutic approaches have been investigated, such as passive immunotherapy with antiserum to the lipopolysaccharide (LPS) or endotoxin core of gram-negative bacteria or treatment with corticosteroids or opiate antagonists. However, despite successes in animal models [5-10], well-designed clinical trials using either high-dose corticosteroids or naloxone have failed to demonstrate an increased survival of patients with septic shock [11-14].

The concept of passive immunotherapy with antiserum to the endotoxin core of gram-negative bacteria relies on the following considerations. Among gram-negative bacteria, the central part of the LPS (the core glycolipid, which is made up of lipid A and the core oligosaccharide) is a highly conserved struc-

We thank Drs. J. D. Baumgartner and J. Bille (Lausanne) for help in clinical analysis; Dr. G. Van Melle for advice in statistical analysis; Prof. C. Perret, Prof. J. Freeman, Dr. R. Chiolero (Lausanne), Prof. J. M. C. Douze, Dr. P. F. Hulstaert, Dr. L. E. C. Verhoeven-Van Duin (Utrecht), Dr. J. S. F. Gimbrère (Nijmegen), Dr. D. Scheidegger (Basel), Prof. C. P. Baumann (Zurich), Dr. J. F. Enrico (Neuchâtel), and Dr. J. J. Amacker (Sion) for allowing us to study patients in their intensive care units; and Sandoz AG (Dr. J. Schädelin), Sandoz Forschungsinstitut (Prof. R. Czok and Dr. H. Bachmayer), and the Central Laboratory of the Swiss Red Cross (Prof. A. Hässig) for supplies of test material and help in conducting the study.

Please address requests for reprints to Dr. Michel P. Glauser, Division of Infectious Diseases, Department of Internal Medicine, Centre Hospitalier Universitaire Vaudois, CH-1011 Lausanne, Switzerland. 
ture [15], in contrast to the outer part, which is composed of repeating units of oligosaccharides $(\mathrm{O}$-side chains) that are antigenically highly variable [16]. Rough mutants of gram-negative bacteria are characterized by defective LPS lacking the O-side chains; thus, they present on their surface a core glycolipid accessible for immunologic reactions [17]. Because most of the toxic effects of endotoxin are mediated by the lipid A moiety of the LPS [18, 19], it has been hypothesized that immunization with rough mutants of gram-negative bacteria might induce antibodies to core glycolipid, which could reduce the morbidity and mortality of gram-negative infections.

In experimental animal models, passive immunization with two of these mutants - the J5 mutant of Escherichia coli O111:B4 and the R595 mutant of Salmonella minnesota S218 - prevented ( $I$ ) death after lethal challenge with various gram-negative bacteria or endotoxins [20-23], (2) localized and generalized Shwartzman reactions after injection of endotoxins [24-27], and (3) hypotension after injection of endotoxins [28].

In humans, immunotherapy with serum obtained after immunization of volunteers with $E$. coli J5 vaccine (antiserum to $E$. coli J5) was shown by Ziegler et al. [4] to significantly reduce the mortality of gramnegative bacteremia and shock. More recently, Baumgartner et al. [29], in a prophylactic study, showed that J5-immune plasma prevented the development of gram-negative septic shock and death in surgical patients at high risk of infection.

However, for practical reasons, which are mainly due to difficulties in storage and administration, antiserum to $E$. coli $\mathrm{J} 5$ is not suitable for clinical use on a large scale. In comparison with antiserum to $E$. coli J5, a purified IgG preparation obtained from pooled plasma of volunteers immunized with $E$. coli J5 (J5-IVIG) might offer many advantages. First, such a preparation might be available in a lyophilized form, suitable for long-term preservation, and would not require matching of blood groups. Second, the iv route of administration may allow infusion of large quantities of the potentially active principal.

We therefore conducted a double-blind, randomized, multicenter study to determine whether therapy with J5-IVIG would be as effective as antiserum to $E$. coli $\mathrm{J} 5$ in reducing the mortality of gram-negative septic shock. Control patients were treated with a standard IgG preparation (IVIG).

\section{Materials and Methods}

The trial was conducted in medical and surgical intensive care units of eight Swiss and two Dutch medical centers from March 1984 to March 1986.

Patients' eligibility. Patients eligible for the study were those who fulfilled the following two criteria: (I) the presence or the high likelihood of a gramnegative bacteremia (i.e., a gram-negative bacteremia, a proven or firmly suspected gram-negative focal infection, or a clinical condition predisposing to gramnegative infection [granulocytopenia, septic abdominal surgery, esophageal surgery, or surgery for ruptured aortic aneurysma]); and (2) the presence of septic shock, defined by a systolic blood pressure of $<90$ $\mathrm{mm} \mathrm{Hg}$ or a decrease of $>\mathbf{3 0 ~} \mathrm{mm} \mathrm{Hg}$ in a hypertensive patient in the absence of other causes of shock, such as hypovolemia, myocardial infarction, and pulmonary embolism. In addition, patients had to present at least one of the following signs: oliguria $(<30$ $\mathrm{mL} / \mathrm{h})$, hypothermia $(<36 \mathrm{C})$, hypoxemia $\left(\mathrm{PO}_{2}\right.$ of $<70 \mathrm{~mm} \mathrm{Hg}$ ), respiratory alcalosis ( $\mathrm{pH}$ of $>7.50$ or $\mathrm{PCO}_{2}$ of $<30 \mathrm{~mm} \mathrm{Hg}$ ), metabolic acidosis ( $\mathrm{pH}$ of $<7.3$ or base excess of $<-10 \mathrm{mmol} / \mathrm{L}$ ), coagulation abnormalities (plasma thromboplastin level of $<50 \%$ of normal, $>40 \mathrm{~s}$, or elevation in levels of fibrin split products), and thrombocytopenia $\left(<100000 / \mathrm{mm}^{3}\right.$ or a decrease of $>50 \%$ of a previously normal value).

Randomization procedure. A computer-generated randomization list was established for each participating center. This list was stratified so that an equal number of patients would be randomized to each group, with every four patients in each center. Patients were randomly assigned to a treatment group by following the numerical order of the randomization list.

Treatment and materials. As a prerequisite to study entry, the patient had to be admitted to the intensive care unit and had to receive standard therapy for septic shock (fluid resuscitation, vasopressors, and antibiotic treatment) as well as all necessary supportive measures required by his or her clincial condition (Swan-Ganz catheterization, artificial ventilation, and hemodialysis).

At randomization, patients received a single dose of $200 \mathrm{mg} / \mathrm{kg}$ of body weight (maximal dose, $12 \mathrm{~g}$ ) of either J5-IVIG or standard IVIG. Lyophilized immunoglobulins were reconstituted with pyrogen-free $\mathrm{NaCl}$ to a final concentration of $3 \%$ and infused in a 60-min period. IVIG (Sandoglobulin ${ }^{\circledR}$; Sandoz, 
Basel, Switzerland) was prepared from a pool of 8000 individual blood donations [30], whereas J5-IVIG was prepared from a pool of 600 plasma specimens collected from 70 volunteers immunized two times at a one-week interval with $E$. coli $\mathrm{J} 5$ vaccine. The $\mathrm{J} 5$ vaccine was prepared from $E$. coli O111:B4 J5 bacterial cells (the $\mathrm{J} 5$ mutant of $E$. coli O111:B4 was provided by Dr. E. Ziegler, San Diego, Calif) cultured overnight in Trypticase ${ }^{\circledR}$ soy broth (Difco, Detroit). After centrifugation, the cells were washed with sterile PBS (pH 7.2) and boiled (100 C) for $2.5 \mathrm{~h}$. The bacterial concentration was adjusted spectrophotometrically to $10^{10} \mathrm{bacteria} / \mathrm{mL}$. Thimerosal was added to a final concentration of $0.1 \mathrm{mg} / \mathrm{mL}$ (Sandoz Forschungsinstitut, Vienna). The immunization doses were $5 \times 10^{9}$ bacterial cells on day 1 and $10^{10}$ on day 8 . Antiserum to $E$. coli $\mathrm{J} 5$ was harvested at weekly intervals, starting one week after the second immunization (AB-O Plasma, Munich, Federal Republic of Germany). Both study preparations were IgG fractions processed at $\mathrm{pH} 4$ (Central Laboratory of the Swiss Red Cross, Bern, Switzerland) [30, 31]. Using an ELISA technique for quantifying antibodies to the LPS of E. coli J5, the J5IVIG preparation had a 2.2-fold increase in ELISA titers when compared with the IVIG preparation. Similar results were obtained by Stoll et al. [32] in testing these two preparations ( 2.8 -fold increase in mean ELISA titer).

Case review and data analysis. Clinical course and laboratory findings were recorded by the local investigators until death or clinical cure of infection. To ensure uniformity in data collection and case reviewing, the following procedure was adopted: Each patient's clinical course was reviewed by one investigator (T.C.), who prepared a case abstract and a report form for computer analysis. Case abstracts were presented blindly to a physician not involved in the present study (Dr. J.-D. Baumgartner). All cases with diagnostic problems or complicated clinical courses were then discussed with a group of infectious disease specialists blinded to the allocated regimen (M.P.G., Dr. J. Bille, and Dr. J.-D. Baumgartner) until a consensus was reached on the patient's eligibility, microbiological documentation of septic shock, and outcome. Report forms were then entered into the computer, and no further changes were allowed.

Definitions and clinical evaluation. The final diagnosis of gram-negative septic shock required the presence of a documented gram-negative infection, i.e., a gram-negative bacteremia or a gram-negative focal infection with negative cultures of blood. The isolated gram-negative organism was considered to be the etiologic agent of sepsis if recovered within a 24-h period before or after the onset of shock. Positive cultures of blood taken postmortem were disregarded. The adequacy of the antibiotic treatment was based on the susceptibility pattern of the causative agent of gram-negative sepsis. This evaluation was not made later than $48 \mathrm{~h}$ after randomization. The severity of the underlying disease was reported according to the classification proposed by McCabe and Jackson [33]. Systemic complications of septic shock were reported only if absent at the time of randomization. Death was attributed to septic shock if the patient died of irreversible shock, of a direct consequence of shock (i.e., multiple organ failure), or of a complication of infection (i.e., diffuse hemorrhage related to disseminated intravascular coagulation). Other causes of death were attributed to the underlying disease or diseases.

Study design and statistical analyses. The principal study end point was the mortality of gramnegative septic shock. Secondary end points were the reversal of gram-negative septic shock and time to death in septic shock. According to a previous study by Ziegler et al. [4], an assumption was made that the proportion of death in the control group would be 0.7 . To detect a reduction of $50 \%$ in the death rate with J5-IVIG treatment at error rates of $\alpha=$ 0.05 and $\beta=0.10$ (i.e., a study power of 0.9 ), 51 patients with documented gram-negative septic shock would be needed in each treatment group [34]. The number of patients with gram-negative septic shock required by a three-arm, placebo-controlled trial precluded the feasibility of such a study. Statistical analyses of clinical and laboratory data were done using the $\chi^{2}$ test or Fisher's exact test for comparisons of proportions and the Kruskall-Wallis test for nonparametric variables. All reported significance levels are two sided.

\section{Results}

During a two-year period, 100 patients were randomized into the study. Eleven patients were excluded from the analysis: 10 patients because shock either was not present at study entry or was not due to sepsis (two patients in the IVIG group and eight patients in the J5-IVIG group) and one patient receiving J5-IVIG because he did not receive the ade- 
Table 1. Characteristics of patients with gram-negative septic shock.

\begin{tabular}{lll}
\hline Characteristic & \multicolumn{1}{c}{ J5-IVIG } & \multicolumn{1}{c}{ IVIG } \\
\hline No. of patients & 30 & 41 \\
Age $(y)^{*}$ & $52(7-76)$ & $58(19-78)$ \\
Male/female ratio & $19 / 11$ & $25 / 16$ \\
Body weight (kg)* & $67(35-100)$ & $70(45-120)$ \\
Underlying disease ${ }^{\dagger}$ & & \\
$\quad$ Rapidly fatal & $3(10)$ & $2(5)$ \\
$\quad$ Ultimately fatal & $6(20)$ & $12(29)$ \\
$\quad$ Nonfatal & $21(70)$ & $27(66)$ \\
Malignancies & $5(17)$ & $10(24)$ \\
$\quad$ Hematologic & 4 & $5 \ddagger$ \\
$\quad$ Nonhematologic & 1 & $6 \ddagger$ \\
Neutropenia $\left(<1000\right.$ cells $\left./ \mathrm{mm}^{3}\right)$ & $3(10)$ & $5(12)$ \\
\hline
\end{tabular}

NOTE. The $P$ values for comparisons of treatment groups are not significant for all parameters.

* Values are medians (range).

$\dagger$ Data are no. of patients (percentage of group).

$\ddagger$ One patient presented with two malignancies.

quate dosage of immunoglobulins. Inclusion of these 11 patients in the overall evaluation would not have modified the results. Of the 89 remaining patients with septic shock, 71 had documented gram-negative shock, 5 had documented gram-positive shock, and 4 had shock due to documented yeast infections. In nine patients the cause of shock could not be established as microbial because all cultures remained negative. Thus, we report here on the outcome of the 71 patients with documented gram-negative septic shock.

Patients' characteristics. Table 1 shows the characteristics of the 71 patients with gram-negative septic shock. Thirty patients were treated with J5-IVIG and 41 patients with IVIG. The two treatment groups were similar for age, sex, body weight, and severity of the underlying disease. Seventy percent of the patients had a nonfatal disease. Malignancies were present in $17 \%$ and $24 \%$ of the patients, respectively. Half of the patients with cancer were neutropenic $\left(<1000\right.$ cells $\left./ \mathrm{mm}^{3}\right)$ at randomization. Overall, $41 \%$ of the patients were admitted to medical intensive care units and $59 \%$ to surgical intensive care units.

Clinical data at randomization. At randomization, the two treatment groups were similar with regard to the hemodynamic and respiratory parameters and received equally adequate supportive and therapeutic measures (table 2). The median duration of shock before administration of the trial preparations was $12 \mathrm{~h}$ (range, 2-36 h) in patients treated with J5-
Table 2. Clinical data at randomization.

\begin{tabular}{llc} 
Clinical parameter & $\begin{array}{c}\text { J5-IVIG } \\
(n=30)\end{array}$ & $\begin{array}{c}\text { IVIG } \\
(n=41)\end{array}$ \\
\hline Duration of shock $(\mathrm{h})$ & $12(2-36)$ & $10(3-144)$ \\
Vasopressor therapy & $23(77)$ & $35(85)$ \\
$\quad$ Dose $(\mu \mathrm{g} / \mathrm{kg}$ per min) & $11(3-30)$ & $8(2-50)$ \\
Median arterial pressure & & \\
$\quad(\mathrm{mm} \mathrm{Hg)}$ & $90 / 50$ & $90 / 40$ \\
Diuresis $(\mathrm{mL} / \mathrm{h})$ & $17(0-170)$ & $8(0-190)$ \\
Oxygen support & $27(90)$ & $35(85)$ \\
$\quad$ Median Flo & 0.5 & 0.45 \\
High-dose corticosteroids & $11(37)$ & $14(34)$ \\
Antibiotic treatment & $23(77)$ & $33(80)$ \\
$\quad 1$ antibiotic & 6 & 7 \\
$\quad \geqslant 2$ antibiotics & 17 & 26 \\
Dose of immunoglobulins $(\mathrm{g})$ & $12(7-12)$ & $12(8-12)$ \\
\hline
\end{tabular}

NOTE. Data are medians (range) or no. of patients (percentage of group). The $P$ values for comparisons of treatment groups are not significant for all parameters. $\mathrm{FlO}_{2}=$ fractional inspired oxygen concentration.

IVIG and $10 \mathrm{~h}$ (range, 3-144 h) in those treated with IVIG. Eighty percent of the patients required vasopressor therapy (median dose, $11 \mu \mathrm{g} / \mathrm{kg}$ per min in the J5-IVIG group and $8 \mu \mathrm{g} / \mathrm{kg}$ per min in the IVIG group). Despite this adrenergic support, the median arterial pressure was $90 / 50 \mathrm{~mm} \mathrm{Hg}$ in the J5-IVIG group and $90 / 40 \mathrm{~mm} \mathrm{Hg}$ in the IVIG group, levels resulting in severe oliguria in most of the patients (median diuresis, 17 and $8 \mathrm{~mL} / \mathrm{h}$, respectively). In both groups, $\sim 90 \%$ of the patients required oxygen support, with a median $\mathrm{FIo}_{2}$ in the range of $0.45-0.50$. One-third of the patients had received high-dose corticosteroids before randomization. At study entry $77 \%$ of the J5-IVIG-treated patients and $80 \%$ of the IVIG-treated patients were already receiving antibiotic therapy. In most of the patients, the antibiotic treatment consisted of a combination of a $\beta$-lactam antibiotic and an aminoglycoside. In all but two patients (one patient in each group), the maximal dose of $12 \mathrm{~g}$ of immunoglobulins was infused without side effects. Fifteen minutes after the infusion of J5-IVIG, one patient developed a hypertensive crisis (blood presure, $225 / 90 \mathrm{~mm} \mathrm{Hg}$ ) that lasted $25 \mathrm{~min}$ and from which he recovered uneventfully. The other patient presented a transient cutaneous rash during the infusion of IVIG.

Documentation of gram-negative septic shock and antibiotic susceptibility. A gram-negative bacteremia was documented in $23(77 \%)$ of 30 patients treated with J5-IVIG and in $28(68 \%)$ of 41 patients 
Table 3. Documentation of gram-negative septic shock and organisms isolated in episodes of gram-negative bacteremia.

\begin{tabular}{|c|c|c|c|}
\hline Category, infection type & $\begin{array}{l}\text { J5-IVIG } \\
(n=30)(\end{array}$ & $\begin{array}{c}\text { IVIG } \\
(n=41)\end{array}$ & $\begin{array}{c}\text { Total } \\
(n=71)\end{array}$ \\
\hline \multicolumn{4}{|l|}{ Documentation of shock } \\
\hline \multicolumn{4}{|l|}{ Gram-negative } \\
\hline bacteremia & $23(77)$ & $28(68)$ & $51(72)$ \\
\hline Single organism & 19 & 21 & \\
\hline \multicolumn{4}{|l|}{ Multiple organisms } \\
\hline \multicolumn{4}{|l|}{ Pure gram-negative } \\
\hline rods & 1 & 3 & \\
\hline $\begin{array}{l}\text { Mixed (gram- } \\
\text { negative rods and } \\
\text { other organisms)* }\end{array}$ & 3 & 4 & \\
\hline \multicolumn{4}{|l|}{ Focal gram-negative } \\
\hline infections & $7(23)$ & $13(32)$ & $20(28)$ \\
\hline \multicolumn{4}{|l|}{$\begin{array}{l}\text { Organisms in gram-nega- } \\
\text { tive bacteremia }\end{array}$} \\
\hline E. coli & 9 & 6 & $15(26)$ \\
\hline Pseudomonas sp. & 7 & 8 & $15(26)$ \\
\hline Klebsiella sp. & 5 & 3 & $8(14)$ \\
\hline Other gram-negative rods $\dagger$ & 5 & 15 & $20(34)$ \\
\hline
\end{tabular}

NOTE. Numbers in parentheses are percentages of the group. The $P$ values for comparisons of treatment groups are not significant for all parameters.

* In a few instances, gram-positive cocci or yeasts were isolated together with gram-negative rods: six streptococci (three Streptococcus faecalis, two Streptococcus pneumoniae, and one Streptococcus pyogenes), one Staphylococcus epidermidis, and one Candida albicans.

$\dagger$ Neisseria meningitidis (five cases), Serratia marcescens (four cases), Enterobacter spp. (three cases), and Bacteroides spp. (three cases) that were isolated with other gram-negative bacteria-Proteus spp. (three cases), Citrobacter freundii (one case), and Acinetobacter anitratus (one case).

treated with IVIG (table 3). Episodes of polymicrobial bacteremia occurred in 11 cases (four patients receiving J5-IVIG and seven patients receiving IVIG), of which four were pure gram-negative bacteremias and seven were mixed bacteremias (gram-negative rods and gram-positive cocci in six patients and a gram-negative rod and a yeast in one patient). In the remaining patients, gram-negative organisms were isolated from a primary infectious site but cultures of blood remained sterile, possibly because these patients were receiving broad-spectrum antibiotics when blood for cultures was drawn. The various gram-negative rods isolated from cultures of blood were equally distributed among the two treatment groups (table 3 ).

In 23 patients $(77 \%)$ in the J5-IVIG group and in 34 patients $(83 \%)$ in the IVIG group, the organ-
Table 4. Results of immunoglobulin therapy and outcome of patients with gram-negative septic shock.

\begin{tabular}{lcc}
\hline Clinical parameter & J5-IVIG & IVIG \\
\hline $\begin{array}{l}\text { Results of treatment } \\
\text { Vasopressor therapy }\end{array}$ & $30(100)$ & $41(100)$ \\
$\quad$ Duration (d) & $2(0-30)$ & $3(0-16)$ \\
$\quad$ Dose $(\mu \mathrm{g} / \mathrm{kg}$ per min) & $10(0-30)$ & $7(2-30)$ \\
Duration of intubation (d) & $7(0-52)$ & $11(0-39)$ \\
Systemic complications & & \\
$\quad$ of septic shock & $17(57)$ & $24(58)$ \\
Reversal of shock & $21(70)$ & $33(80)$ \\
$\quad$ Transient & 8 & 14 \\
$\quad$ Definitive & 13 & 19 \\
Time to reversal of shock & $16(1-312)$ & $36(0-240)$ \\
$\quad$ (h) & $17(57)$ & $22(54)$ \\
Outcome of patients & $15(50)$ & $20(49)$ \\
Overall mortality & $2(7)$ & $2(5)$ \\
$\quad$ Septic shock & & \\
$\quad$ Underlying disease & $7(0-32)$ & $9(0-39)$ \\
Time to death in &
\end{tabular}

NOTE. Data are no. of patients (percentage of group) or median values (range). The $P$ values for comparisons of treatment groups are not significant for all parameters.

ism or organisms isolated were susceptible to all the antibiotics administered. In all but one of the remaining patients, at least one antibiotic was active against the primary pathogen. One patient treated with J5IVIG was infected with a multiresistant $A$. anitratus, which was only intermediately sensitive to ciprofloxacin.

Results of immunoglobulin therapy. Table 4 summarizes the results of treatment with either J5IVIG or IVIG. No difference was observed between the two treatment groups. The duration and dose of vasopressor therapy, the duration of respiratory assistance, and the development of systemic complications of shock were similar in each treatment group. Shock was reversed in 21 patients $(70 \%)$ who received J5-IVIG and in 33 patients $(80 \%)$ who received IVIG. However, this reversal of shock was only transient in eight $(38 \%)$ of 21 patients and $14(42 \%)$ of 33 patients, respectively. The median time to reversal of shock was $16 \mathrm{~h}$ in the J5-IVIG group and $36 \mathrm{~h}$ in the IVIG group $(P=.75)$.

Outcome of patients. The mortality of patients with gram-negative septic shock is reported in table 4. Overall, $57 \%$ of the patients in the J5-IVIG group died, and $54 \%$ in the IVIG group died. The mortality of septic shock was $50 \%$ and $49 \%$, respectively, and there was no trend toward a difference in mor- 
tality at any point during follow-up. In each treatment group two deaths were due to the underlying diseases. Also, J5-IVIG did not result in a prolongation of survival of those patients eventually dying of septic shock. Moreover, the duration of shock at randomization did not influence the outcome. Indeed, the mortality of patients treated in the early phase $(\leqslant 6 \mathrm{~h})$ of shock was similar to that of patients with advanced shock $(>6 \mathrm{~h})$ at randomization $(43 \%$ vs. $46 \%$, respectively). Finally, the mortality was $100 \%$ (5 of 5 ) in patients with rapidly fatal diseases, compared with only $44 \%$ ( 8 of 18 patients) and $50 \%$ (24 of 48 patients) in those with, respectively, ultimately fatal and nonfatal diseases $(P=.08)$. Thus, in patients with gram-negative septic shock, treatment with J5-IVIG did not prove to be superior to treatment with IVIG in reversing septic shock, reducing mortality, or prolonging the survival of those patients ultimately dying.

\section{Discussion}

Because serum from volunteers immunized with E. coli J5 protected against death due to gramnegative bacteremia and septic shock $[4,29]$, we investigated whether an IgG fraction prepared from pooled human plasma from volunteers immunized similarly would retain the protective activity. However, therapy with J5-IVIG was not superior to treatment with IVIG either in reducing the mortality of gram-negative septic shock or in reversing shock. In addition, the use of J5-IVIG neither delayed the occurrence of septic deaths nor reduced the development of systemic complications of shock.

With 71 patients ( 30 in the J5-IVIG group and 41 in the IVIG group) presenting with documented gram-negative shock, the study had a power of 0.78 to detect, at an $\alpha$ error rate of 0.05 , a reduction of the mortality from $70 \%$ in the control group to $35 \%$ in the J5-IVIG group. Thus, the study did have sufficient power to detect such a difference in mortality. From these results, however, we cannot infer that both treatment regimens were ineffective because the study did not include a placebo group.

The discrepancy between the success of antiserum to $E$. coli $\mathrm{J} 5$ in preventing and treating gram-negative septic shock in previous trials $[4,29]$ and the failure of J5-IVIG in the present study might be due, at least partly, to several factors.

First, many patients presented at study entry with advanced, possibly irreversible, septic shock, as re- vealed by a median duration of shock of $12 \mathrm{~h}$ in the J5-IVIG group and $10 \mathrm{~h}$ in the IVIG group. However, when the outcome of patients was related to the duration of shock at randomization, patients enrolled early during shock ( $\leqslant 6 \mathrm{~h}$ after shock developed) apparently did not have a better outcome than the patients randomized later on. Moreover, Ziegler et al. [4] previously showed that the efficacy of antiserum to $E$. coli $\mathrm{J} 5$ was most pronounced for the subset of patients in profound shock at randomization (i.e., requiring vasopressor therapy for $>6 \mathrm{~h}$ ).

Second, the difference in titers of antibody to E. coli J5 LPS, as measured by ELISA, was only 2.2fold between the J5-IVIG and the control preparation, a difference that might be insufficient to afford increased protection against gram-negative septic shock. Furthermore, recent experimental results suggest that antibodies with the most cross-reactive properties for various gram-negative bacteria are directed against antigenic determinants of the Re LPS, which consists of lipid A and ketodeoxyoctonate, and not against those of $E$. coli $\mathrm{J} 5$ [35]. As recently demonstrated by Stoll et al. [32], the titers of antibody to Re LPS in the J5-IVIG preparation used in the present study were not different from those in the IVIG control preparation.

Third, both the J5-IVIG and the IVIG preparations lack antibodies of the IgM class, which might be the protective factors present in antiserum to E. coli $\mathrm{J} 5$. However, clinical data suggesting that cross-protective antibodies are of the IgM class are limited to a study in patients with Pseudomonas aeruginosa bacteremia. In these patients, core-specific antibodies of the IgM isotype predicted survival more significantly than those of the IgG isotype [36]. Yet, in contrast to these results, preliminary data in the present study failed to demonstrate a correlation between survival and core-specific antibodies of the IgG or IgM class (J. D. Baumgartner, personal communication).

Fourth, the J5-IVIG preparation also lacked serum or plasma factors that have been recently recognized as neutralizing [37], interacting with [38], or binding to LPS [39], all factors that might also account for the difference in efficacy obtained with antiserum to $E$. coli $\mathrm{J} 5$ and J5-IVIG.

Finally, recent experimental studies strongly suggest that tumor necrosis factor/cachectin is a primary mediator of endotoxic shock $[40,41]$ and that antibodies to tumor necrosis factor/cachectin might prevent some of its manifestations $[42,43]$. Thus, the reduc- 
tion of mortality observed in previous clinical trials with antiserum to $E$. coli $\mathrm{J} 5$ and not with J5-IVIG could conceivably be due to the interference of the antiserum with tumor necrosis factor/cachectin.

In conclusion, the present study clearly stresses the need for further in vitro and clinical studies to understand how antiserum to $E$. coli $\mathrm{J} 5$ and plasma from volunteers immunized with $E$. coli $\mathrm{J} 5$ has been so impressively effective in the treatment and prophylaxis of gram-negative septic shock, whereas the J5-IVIG fraction we tested was apparently ineffective. In particular, future studies should not only address the important issue of the epitope or epitopes of the LPS that stimulate the production of crossprotective antibodies, but also determine which class of antibody (IgG or IgM) or serum factors are the mediators of this protection.

\section{References}

1. Wolff SM, Bennett JV. Gram-negative-rod bacteremia [editorial]. N Engl J Med 1974;291:733-4

2. Kreger BE, Craven DE, Carling PC, McCabe WR. Gramnegative bacteremia. III. Reassessment of etiology, epidemiology and ecology in 612 patients. Am J Med 1980; 68:332-43

3. Bryan CS, Reynolds KL, Brenner ER. Analysis of 1,186 episodes of gram-negative bacteremia in non-university hospitals: the effects of antimicrobial therapy. Rev Infect Dis 1983;5:629-38

4. Ziegler EJ, McCutchan JA, Fierer J, Glauser MP, Sadoff JC, Douglas H, Braude AI. Treatment of gram-negative bacteremia and shock with human antiserum to a mutant Escherichia coli. N Engl J Med 1982;307:1225-30

5. Fabian TC, Patterson R. Steroid therapy in septic shock. Survival studies in a laboratory model. Am Surg 1982;48:614-7

6. Hinshaw LB, Archer LT, Beller-Todd BK, Coalson JJ, Flournoy DJ, Passey R, Benjamin B, White GL. Survival of primates in $\mathrm{LD}_{100}$ septic shock following steroid/antibiotic therapy. J Surg Res 1980;28:151-70

7. Hinshaw LB, Archer LT, Beller-Todd BK, Benjamin B, Flournoy DJ, Passey R. Survival of primates in lethal septic shock following delayed treatment with steroid. Circ Shock 1981;8:291-300

8. Holaday JW, Faden AI. Naloxone reversal of endotoxin hypotension suggests role of endorphins in shock [letter]. Nature 1978;275:450-1

9. Faden AI, Holaday JW. Experimental endotoxin shock: the pathophysiologic function of endorphins and treatment with opiate antagonists. J Infect Dis 1980;142:229-38

10. Reynolds DG, Gurll NJ, Vargish T, Lechner RB, Faden AI, Holaday JW. Blockade of opiate receptors with naloxone improves survival and cardiac performance in canine endotoxic shock. Circ Shock 1980;71:39-48

11. Sprung CL, Caralis PV, Marcial EH, Pierce M, Gelbard MA, Long WM, Duncan RC, Tendler MD, Karpf M. The effects of high-dose corticosteroids in patients with septic shock. A prospective, controlled study. N Engl J Med 1984;311:1137-43

12. Bone RC, Fisher CJ Jr, Clemmer TP, Slotman GJ, Metz CA, Balk RA, the Methylprednisolone Severe Sepsis Study Group. A controlled clinical trial of high-dose methylprednisolone in the treatment of severe sepsis and septic shock. N Engl J Med 1987;317:653-8

13. The Veterans Administration Systemic Sepsis Cooperative Study Group. Effect of high-dose glucocorticoid therapy on mortality in patients with clinical signs of systemic sepsis. N Engl J Med 1987;317:659-65

14. DeMaria A, Craven DE, Heffernan JJ, McIntosh TK, Grindlinger GA, McCabe WR. Naloxone versus placebo in treatment of septic shock. Lancet 1985;1:1363-5

15. Rietschel ET, Wollenweber H-W, Russa R, Brade H, Zähringer U. Concepts of the chemical structure of lipid A. Rev Infect Dis 1984;6:432-8

16. Westphal O, Jann K, Himmelspach K. Chemistry and immunochemistry of bacterial lipopolysaccharides as cell wall antigens and endotoxins. Prog Allergy 1983;33:9-39

17. Jansson P-E, Lindberg AA, Lindberg B, Wollin R. Structural studies on the hexose region of the core in lipopolysaccharides from Enterobacteriaceae. Eur J Biochem 1981; 115:571-7

18. Rietschel ET, Schade U, Jensen M, Wollenweber H-W, Lüderitz O, Greisman SG. Bacterial endotoxins: chemical structure, biological activity and role in septicaemia. Scand J Infect Dis [Suppl] 1982;31:8-21

19. Young LS. Gram-negative sepsis. In: Mandell GL, Douglas RG Jr, Bennett JE, eds. Principles and practice of infectious diseases. 2nd ed. New York: 1985:452-75

20. McCabe WR, Greely A. Immunization with $R$ mutants of S. minnesota. I. Protection against challenge with heterologous gram-negative bacilli. J Immunol 1972;108:601-10

21. Ziegler EJ, Douglas H, Sherman JE, Davis CE, Braude AI. Treatment of $E$. coli and klebsiella bacteremia in agranulocytic animals with antiserum to a UDP-Gal epimerase-deficient mutant. J Immunol 1973;111:433-8

22. Ziegler EJ, McCutchan JA, Douglas H, Braude AI. Prevention of lethal pseudomonas bacteremia with epimerasedeficient $E$. coli antiserum. Trans Assoc Am Physicians 1975;88:101-8

23. Marks MI, Ziegler EJ, Douglas H, Corbeil LB, Braude AI. Induction of immunity against lethal Haemophilus influenzae type b infection by Escherichia coli core lipopolysaccharide. J Clin Invest 1982;69:742-9

24. Ziegler EJ, Douglas H, Braude AI. Human antiserum for prevention of the local Shwartzman reaction and death from bacterial lipopolysaccharides. J Clin Invest 1973;52:3236-8

25. Braude AI, Douglas H. Passive immunization against the local Shwartzman reaction. J Immunol 1972;108:505-12

26. Braude AI, Douglas H, Davis CE. Treatment and prevention of intravascular coagulation with antiserum to endotoxin. J Infect Dis 1973;128(Suppl):S157-64

27. Davis CE, Ziegler EJ, Arnold KF. Neutralization of meningococcal endotoxin by antibody to core glycolipid. J Exp Med 1978;147:1007-17

28. Young LS, Stevens $P$, Ingram J. Functional role of antibody against "core" glycolipid of Enterobacteriaceae. J Clin Invest $1975 ; 56: 850-61$ 
29. Baumgartner J-D, Glauser MP, McCutchan JA, Ziegler EJ, van Melle G, Klauber MR, Vogt M, Muehlen E, Luethy R, Chiolero R, Geroulanos S. Prevention of gram-negative shock and death in surgical patients by antibody to endotoxin core glycolipid. Lancet 1985;2:59-63

30. Kistler P, Nitschmann H. Large scale production of human plasma fractions. Eight years experience with the alcohol fractionation procedure of Nitschmann, Kistler and Lergier. Vox Sang 1962;7:414-24

31. Barandun $S$, Kistler $P$, Jeunet $F$, Isliker $H$. Intravenous administration of human $\gamma$-globulin. Vox Sang 1962;7:157-74

32. Stoll BJ, Pollack M, Hooper JA. Antibodies to endotoxin core determinants in normal subjects and in immune globulins for intravenous use. Serodiagnosis and Immunotherapy 1987;1:21-31

33. McCabe WR, Jackson GG. Gram-negative bacteremia. I. Etiology and ecology. Arch Intern Med 1962;110:847-55

34. Fleiss JL. Statistical methods for rates and proportions. New York: Wiley, 1973

35. Baumgartner JD, O'Brien TX, Kirkland TN, Glauser MP, Ziegler EJ. Demonstration of cross-reactive antibodies to smooth gram-negative bacteria in antiserum to Escherichia coli J5. J Infect Dis 1987;156:136-43

36. Pollack M, Huang AI, Prescott RK, Young LS, Hunter KW, Cruess DF, Tsai C-M. Enhanced survival in Pseudomonas aeruginosa septicemia associated with high levels of circulating antibody to Escherichia coli endotoxin core. J Clin Invest 1983;72:1874-81

37. Warren HS, Novitsky TJ, Ketchum PA, Roslansky PF, Kania S, Siber GR. Neutralization of bacterial lipopolysaccharides by human plasma. J Clin Microbiol 1985;22:590-5

38. Tobias PS, McAdam KPWJ, Soldau K, Ulevitch RJ. Control of lipopolysaccharide-high-density lipoprotein interactions by an acute-phase reactant in human serum. Infect Immun 1985;50:73-6

39. Brade L, Brade H. A 28,000 -dalton protein of normal mouse serum binds specifically to the inner core region of bacterial lipopolysaccharide. Infect Immun 1985;50:687-94

40. Tracey KJ, Beutler B, Lowry SF, Merryweather J, Wolpe S, Milsark IW, Hariri RJ, Fahey TJ III, Zentella A, Albert JD, Shires GT, Cerami A. Shock and tissue injury induced by recombinant human cachectin. Science 1986;234:470-4

41. Beutler B, Cerami A. Cachectin: more than a tumor necrosis factor. N Engl J Med 1987;316:379-85

42. Beutler B, Milsark IW, Cerami AC. Passive immunization against cachectin/tumor necrosis factor protects mice from lethal effect of endotoxin. Science 1985;229:869-71

43. Tracey KJ, Fong Y, Hesse DG, Manogue KR, Lee AT, Kuo GC, Lowry SF, Cerami A. Anti-cachectin/TNF monoclonal antibodies prevent septic shock during lethal bacteraemia [letter]. Nature 1987;330:662-4 